\title{
Grecia como camino hacia la libertad: el filohelenismo de José María Heredia*
}

\author{
Eva LATORRE BROTO \\ CCHS-CSIC
}

\begin{abstract}
RESUMEN
José María Heredia (1803-1839) publicó en 1823 el primer poema filoheleno escrito en español con firma de autor, en el que pone en paralelo la independencia de Grecia con la libertad que él deseaba para Cuba. Entre sus documentos personales se ha conservado parte de un libro con poemas filohelenos escritos en francés, en cuyos márgenes escribió las traducciones al español, pero la crítica no ha podido determinar aún ni el título ni el autor de ese libro. La identificación de ese poemario nos permitirá seguir los pasos del filohelenismo en el Caribe como lenguaje de rebelión y libertad.
\end{abstract}

Palabras clave: Filohelenismo, José María Heredia, Independencia de Cuba, mártires de Suli, Claudio Linati, El Iris (México 1826).

Greece as a path of freedom: José María Heredia's philhellenism

\begin{abstract}
José María Heredia published in 1823 the first philhellenic Spanish poem with expressed name of author, which sets in parallel the independence of Greece and the freedom that he wanted for Cuba. His personal files preserve a damaged book with philhellenic poems in French and a Spanish translation written in the margins. Critics have as yet been unable to determine the title of the book and the author to which they belong. The identification of this collection of French poems will allow us to follow the steps of philhellenism in the Caribbean as a language of rebellion and freedom.
\end{abstract}

Key words: Philhellenism, José María Heredia, Cuba, Martyrs of Souli, Claudio Linati, El Iris (Mexico 1826).

* Trabajo realizado en el marco del proyecto de investigación Refa: FFI2011-29696-C0201, adscrito al Instituto de Lenguas y Culturas del Mediterráneo del CCHS-CSIC. El presente texto es una versión ampliada de la comunicación presentada en griego en el congreso internacional sobre Filohelenismo El interés por Grecia y los griegos desde 1821

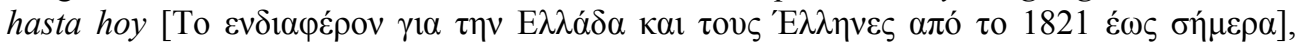
celebrado en Arta (Grecia) del 5 al 7 de julio de 2013. Las cuestiones aquí expuestas son analizadas con mayor profundidad y detalle en mi tesis doctoral, que tengo en vías de finalización. 
SUMARIO: 1.José María Heredia: el Tirteo americano. 2.Los Mártires de Suli en La Habana. 3.José María Heredia y el filohelenismo carbonario (El Iris, México 1826). 4.Sentido y función del Apóstrofe a la Grecia y La muerte de Despo. 5.Cuatro preguntas sin respuesta.

\section{José María Heredia: el Tirteo americano.}

Aun a riesgo de resultar políticamente incorrecta, debo partir de la premisa de que el poeta nacional de Cuba, José María Heredia, era español, dado que su deseo de dejar de serlo es, precisamente, la idea única que vertebra su obra y da sentido a su vida.

José María Heredia (1803-1839) ${ }^{1}$ vivió de cerca la era de las revoluciones, tanto la americana como la española. En 1820 el pronunciamiento militar del General Riego logró que el rey Fernando VII jurara la Constitución en Madrid, pero el nuevo Estado liberal seguía sin satisfacer a los que habían visto que, en su camino desde la Patagonia hasta México, la libertad siempre pasaba rozando Cuba, pero nunca se quedaba en ella.

Con apenas diecinueve años, en mayo de 1823, Heredia ya era celebrado por las élites cubanas como el primer poeta capaz de abrir una nueva etapa en la literatura de la isla (Méndez, 2003: 10). La expresión no es inocente: en aquel contexto social, abrir una nueva etapa significaba romper con los modelos heredados de la colonización española y trabajar en una literatura propiamente cubana que demostrara una identidad diferente. Heredia, sin embargo, no se conformaba con romper con el pasado colonial en el ámbito literario, y se involucró en la insurrección militar que la sociedad secreta de los Caballeros Racionales, estrechamente vinculada a agentes de Simón Bolívar, estaba preparando contra las autoridades españolas para proclamar la República de Cubanacán.

Ya desde sus composiciones más tempranas el joven poeta había deseado emular a Tirteo, el bardo que hinchaba de furor guerrero el corazón de los antiguos espartanos exhortándoles a luchar por la patria y por la libertad. No es casual, por tanto, que la Grecia contemporánea, cuya Guerra de la Independencia contra el Imperio Otomano había estallado en marzo de 1821, le inspirara su Oda a la insurrección de la Grecia en 1820 (sic), que vio la luz el 6 de agosto de 1823 en El Revisor Político y Literario de La Habana, una de las publicaciones más progresistas de la isla. En este largo poema de 231 versos recuerda a los griegos sus antiguas glorias y sus heroicos antepasados —Leónidas, Temístocles, Milcíadespara que recobren sus fuerzas ahogadas por siglos de esclavitud y sacudan las cadenas que los atan a un imperio déspota y decadente. Y tampoco es casualidad que cierren este canto unos versos que han sido considerados como "la primera

${ }^{1}$ Debo señalar que José María Heredia fue tío del poeta francés de origen cubano José María de Heredia (1842-1905), quien llegó a ser uno de los representantes más conspicuos de la escuela parnasiana. 
alusión a Cuba de carácter patriótico y libertario" (Roig, 1941: 41-42) de toda la historia literaria de la isla: el poeta mira a "la risueña Cuba alzar al mar su frente de palmas coronada" y mira a "Grecia lanzar a sus tiranos indignada", mientras sirve de templo a la "alma libertad", y el orbe aplaude "tan glorioso ejemplo".

Este canto a la Grecia en armas sitúa a José María Heredia en línea con la tradición literaria americana durante las guerras contra España de la década de 1810, muy influida por el imaginario clásico de la Revolución Francesa. En los cantos patrióticos de esta época es muy frecuente encontrar, como un recurso para representar la lucha entre libertad y despotismo, el juego cruzado de oposiciones y metáforas en el que los americanos en pugna con los iberos se identifican con los espartanos que resisten frente a las invasiones persas. Heredia actualiza esa metáfora expresándola en términos rabiosamente contemporáneos: la Grecia en conflicto con el Imperio Otomano es la heredera de la Grecia que luchaba contra el Imperio Persa y el espejo de la Cuba en conflicto con el Imperio Español, logrando así la convergencia de esta tradición americana con la corriente ideológica del filohelenismo. En su vertiente política, el filohelenismo, o la admiración exaltada por la Grecia en armas, sirvió de cohesión entre todos los partidarios del espectro político liberal que deseaban terminar con el absolutismo, redivivo en la Europa de la Santa Alianza, mientras que en su vertiente literaria se identificó íntimamente con el romanticismo.

Algunos críticos han visto esta oda como una muestra de la influencia de la tradición clásica en Heredia, interpretación que no la abarca en toda su magnitud ${ }^{3}$, y su estudio en el marco del filohelenismo ha sido, hasta ahora, de escasa relevancia ${ }^{4}$. De esta manera, aún no se ha tenido en cuenta la enorme carga ideológica que conlleva el hecho de que, en una España constitucional naturalmente filohelena, pues consideraba a los griegos como hermanos en lucha por la libertad ${ }^{5}$, el primer

${ }^{2}$ Oda. A la insurrección de la Grecia en 1820, en El Revisor Político y Literario (La Habana), $\mathrm{n}^{\circ}$ 64, 6 de agosto de 1823, pp. 4-8. Reproducido en Roig (1941: 36-48) y Augier (1993: 112-122).

${ }^{3}$ Cf. v. gr., Pérez Asensio (96) y Suárez y Durán (515). Vd. infra nota 10.

${ }^{4}$ Tan sólo hemos encontrado dos referencias que aludan al filohelenismo de Heredia. En primer lugar, Menéndez Pelayo (I, 238-239), quien menciona la oda a los griegos de Heredia para sugerir que su "filohelenismo" parece de "inspiración byroniana", con el fin de ahondar en la idea de que "alguna vez imitó a Byron"; y Cabrera, quien sí la interpreta como una muestra de filohelenismo claramente romántico, pero se limita a comentarla en consonancia con el cuadro de Eugène Delacroix Grecia entre las ruinas de Missolonghi (1826), con algún error grave además, como la afirmación de que Al alzamiento de los griegos contra los turcos en 1821 (segunda versión de la oda que Heredia publicó en 1825), fue escrita en 1820, aunque no publicada hasta 1823. Vd. infra nota 10.

${ }^{5}$ Sobre los primeros contactos políticos entre la Grecia insurrecta y la España liberal (1821-1823), vd. Latorre (2011 y 2012). 
poema filoheleno localizado entre la documentación de la época escrito directamente en español - y no traducido- con nombre expreso de autor sea obra de un independentista cubano.

Otros estudiosos han interpretado este canto a Grecia como la manifestación del irrefrenable sentimiento patriótico del joven poeta, que recurre al prestigio de lo griego para desear una "Cuba independiente, émula de Grecia en libertad y cultura" (Méndez 2003: 151), pero el contexto temporal en el que Heredia publica su oda sugiere que este poema puede encerrar algo más que la mera expresión literaria de un anhelo de libertad.

Como he mencionado antes, esta oda vio la luz el 6 de agosto de 1823, esto es, tan sólo once días antes del 17 de agosto, el día que la sociedad secreta a la que Heredia pertenecía había fijado para la insurrección (Valdés: XXVI) ${ }^{6}$. El estrecho margen de tiempo que media entre ambos acontecimientos invita a pensar que, con su Oda a la insurrección de la Grecia, Heredia está transmitiendo un mensaje en clave con el que los implicados en la conspiración podían fácilmente comprender que la insurrección en la isla estaba ya lista para estallar. No obstante, fuera así o no, lo que resulta evidente es que, en su deseo de convertirse en el nuevo Tirteo americano, Heredia utiliza los recursos de la poética filohelena para convocar a sus conciudadanos a la rebelión (Augier, 1990: 739 y 741 y Méndez, 2003: 150$\left.151^{7}\right)$.

Sin embargo, algo falló. La conspiración fue descubierta tres días antes de que estallara y todos sus cabecillas apresados por las autoridades españolas. Los conjurados tuvieron que esconderse o huir para evitar las represalias, y Heredia escapó en un barco rumbo a Boston. Comenzaba así a los diecinueve años un exilio que terminaría siendo perpetuo, pues tan sólo pudo regresar de visita a su patria una vez antes de morir.

El joven cubano permaneció un par de años en Estados Unidos. A principios de 1825 publicó en Nueva York un volumen con sus poemas, del que excluyó, sin embargo, sus obras de tono más exaltado y patriótico. Al parecer, Heredia conservaba todavía la esperanza de que se le permitiera regresar a Cuba, por lo que no quiso soliviantar los ánimos de las autoridades españolas con soflamas

${ }^{6}$ El jefe de esta conspiración era el habanero José Francisco Lemus, uno de los coroneles de Simón Bolívar en el ejército de Colombia.

${ }^{7}$ Ambos han relacionado este poema con su implicación en esta conspiración, aunque desde un punto de vista descriptivo de la situación emocional de Heredia en aquellos momentos: Augier lo interpreta en función de la necesidad imperiosa que el poeta sentía por emprender la lucha armada, y, para Méndez, esta oda expresa el ansia de Heredia por una rebelión universal contra toda ocupación extranjera. 
independentistas (Piñeyro, 1939: $196^{8}$ ). La Oda a la insurrección de la Grecia en 1820 aparece en esta nueva edición bajo el título Al alzamiento de los Griegos contra los Turcos en 1821, en el que ya figura corregido el error del año en que se produjo la Revolución Griega 9 . El poema está muy retocado, lo que no resulta extraño en Heredia, que reescribía constantemente sus composiciones. Presenta tan sólo 221 versos, y su rasgo más reseñable es la supresión de la polémica estrofa final en la que el poeta mira a Cuba y a Grecia, lo que quizá responda a ese afán por suavizar la carga política de sus poemas, o quizá se deba a que esa estrofa, que bien podía haber sido la convocatoria para la insurrección, había perdido ya su razón de $\operatorname{ser}^{10}$.

La estancia en Estados Unidos fue muy fructífera para Heredia, pero nunca consiguió adaptarse ni al frío ni a su cultura. De ahí que en agosto de 1825 aceptara sin dilaciones la invitación del presidente Guadalupe Victoria para instalarse en México, donde se casó y llegó a desempeñar cargos políticos de relevancia además de seguir con su carrera de escritor y periodista.

José María Heredia nunca perdió el interés por la Grecia moderna, y a lo largo de su obra menciona en varias ocasiones su lucha por la libertad. Admiraba con fervor a Lord Byron, a quien se refirió como "el nuevo Tirteo" que reunió en Grecia

${ }^{8}$ El crítico repara en que esta primera edición de las poesías de Heredia está muy suavizada en cuanto a sus referencias antiespañolas, no incluyendo en ella composiciones como la Oda a Washington, la Epístola a Emilia o La Estrella de Cuba. El tomo con las poesías salió a comienzos de 1825, por lo que ya estaría preparado a finales de 1824, cuando Heredia todavía desconocía la sentencia que en La Habana le condenaba al exilio perpetuo por su implicación con los Caballeros Racionales.

${ }^{9}$ Entre los trabajos consultados, no he hallado que ningún crítico de Heredia justifique el error cronológico que aparece en el título de la primera versión de la oda $A$ la insurrección de Grecia en 1820, ni siquiera con la explicación más simplista, esto es, que se trate de una errata tipográfica. En realidad, la impresión que produce la lectura de esta primera versión del canto a la insurrección de Grecia es que el poeta conocía los acontecimientos griegos, pues eran ampliamente tratados en toda la prensa que pudiera llegar a la isla, pero no sabía exactamente cuándo se habían iniciado. Heredia debió asimilar de forma instantánea la lucha griega con la suya propia contra la dominación española, por lo que no dudó en esgrimirla ante sus correligionarios como ejemplo a seguir sin prestar atención su fecha de inicio, 1820 o 1821, algo irrelevante en aquellos momentos de exaltación y premura ante la inminencia de la sublevación.

${ }^{10}$ Al Alzamiento de los Griegos contra los Turcos en 1821, en Poesías de José María Heredia, Nueva York 1825, pp. 68-75. En Poesías de José María Heredia, (2 ${ }^{\mathrm{a}}$ ed.), vol. II, Toluca (México) 1832, pp. 28-34, el poeta incluyó la tercera y última versión que haría de esta oda con el título A los Griegos, en 1821. Esta versión, que tampoco incluye la alusión a Cuba, está también muy modificada y reducida, pues cuenta con tan sólo 194 versos, y es la más conocida y difundida de las tres. 
a "los proscriptos por la libertad de toda Europa". Así las cosas, resulta sorprendente que sus traducciones del ciclo de Los Mártires de Suli, las primeras y creo que únicas en español, hayan sido prácticamente ignoradas, y más aún cuando cientos de estudiosos han vertido ríos de tinta sobre la vida y la obra del poeta nacional de Cuba.

\section{Los Mártires de Suli en La Habana.}

Cuando Heredia murió en México en 1839, su viuda regresó a La Habana con sus hijos, llevando en su equipaje la biblioteca y el archivo personal de su marido. Casi un siglo después, en 1938, el estudioso cubano Francisco González del Valle describe un "tomo de poesías en francés relativas a la guerra entre turcos y griegos", que se encuentra en el fondo herediano del Museo Nacional de La Habana. Heredia escribió en sus márgenes y blancos las traducciones de diez de ellos, cuyos títulos González del Valle transcribe en francés: Défaite d'Aly Tébélen, Déroute de Mouktar-Veli, Sacrifice des six martyrs souliotes, L'exil de Photos, La prise de Souli, La mort de la magnanime Despo, Hymne funébre sur Parga, y Anathème, traducidos al castellano, y Skilo-Dimos y Yotis mourant, traducidos al italiano. Dado que al libro le faltan las cubiertas y las 24 primeras páginas, González desconoce su título y su autor pero, a partir de las notas personales de otro estudioso cubano llamado José A. Escoto, González aventura que "la obra se titula Chants populaires de la Grèce moderne, de Clark o Charles Jannel" (González del Valle, 1938: 113).

Esto responde, evidentemente, a una lectura errónea de la letra manuscrita de Escoto por Claude-Charles Fauriel. En 1940, cuando Emilio Roig incluye por primera vez estas traducciones en su edición de la Poesía completa de Heredia, descarta que pertenezcan a los Chants populaires, porque esa obra aparece citada como referencia en los comentarios a los poemas, y no puede, por tanto, ser la misma. En cuanto al libro, Roig añade que finaliza en la página 176 y no presenta índice, y por si puede servir de ayuda, transmite que en una de sus páginas puede leerse una nota de Heredia en la que dice que "su autor había escrito con anterioridad un poema titulado La Mérovéide" (Roig: 181-192) 12 .

Con tantas pistas, y gracias sobre todo a la valiosísima edición de esas traducciones manuscritas, no es difícil deducir que esas hojas sueltas pertenecen a un ejemplar de los Chants héroïques des montagnards et matelots Grecs, que Népomucène Lemercier publicó en París en 1824 inspirado directamente por la obra de Fauriel, y que abre con el ciclo de los cantos de Suli, que son nueve en total. Las ocho composiciones traducidas al español se corresponden, pues, con las piezas

${ }^{11} \mathrm{H}$ [eredia], "Poetas ingleses contemporáneos: Lord Byron”, El Iris, I, no 4, pp. 28-29.

${ }^{12}$ Estas traducciones también pueden leerse en Augier (1993: 362-370). Cf. infra nota 29. 
dedicadas a los llamados Mártires de Suli. Es muy probable que Heredia tradujera el ciclo completo, pero los dos primeros poemas se han perdido debido a la falta de las primeras páginas ${ }^{13}$. Un último dato que confirma la identificación de ese libro con los Chants Héroïques es que Lemercier, en efecto, había publicado en 1818 el poema épico titulado La Mérovéide.

Los Chants populaires de la Grèce moderne de Claude Fauriel, obra con la que los críticos cubanos confundieron en un principio este libro de Heredia, marcaron un antes y un después en la concepción del filohelenismo y en la visión que de Grecia se tenía en Europa occidental desde su publicación en París en 1824. Partiendo del principio de la continuidad de la cultura griega, Fauriel declaraba que "los griegos contemporáneos eran herederos directos de una pasión antigua por la libertad", y que su poesía popular "era la expresión directa y auténtica de su carácter y de su espíritu nacional [...], una poesía que vive no en los libros, sino en el pueblo mismo y de toda la vida del pueblo"14. De esta manera, Fauriel también ponía en relación directa las canciones populares de los griegos modernos con la epopeya homérica, y, así, los relatos sobre los cleftes o bandoleros de las montañas y los cantos de Suli merecían ser conocidos y estudiados como lo era Homero.

El ciclo suliota hace referencia al último cerco al que Alí Pachá sometió en 1803 al pueblo de Suli, una ciudadela fortificada e inexpugnable escondida entre las montañas del Epiro, en las inmediaciones de lo que hoy es la frontera griega con Albania. Los asediados resistieron ferozmente hasta la extenuación con episodios de salidas desesperadas y suicidios colectivos, y aunque al final el bey otomano se alzó vencedor, los Mártires de Suli quedaron para siempre marcados en la memoria colectiva griega $-\mathrm{y}$ también en el imaginario liberal europeo- como el símbolo de su indomable y congénito deseo de libertad.

Desde una perspectiva científica, Fauriel ofrecía la versión original griega y la traducción francesa literal en prosa de los cantos que había recopilado como un instrumento para el estudio de la Grecia renacida, pues consideraba que muchos matices del griego podrían perderse forzándolos en verso. Sin embargo, los Chants populaires causaron tal impacto en el poeta y dramaturgo Népomucène Lemercier que pocos meses después publicó su propia versión poética de los cantos, pues,

${ }^{13}$ Los dos primeros cantos del ciclo de Suli según la ordenación de Lemercier son: La famille de Tzavellas y Combat de Moscho. Roig interpreta Anathème como poema independiente, pero en el original de Lemercier figura como el epílogo del Hymne funèbre sur Parga. Anathème, pues, no debería contar por separado, y en honor a la exactitud, deberíamos decir que los poemas de Suli que se han conservado traducidos al español son siete y no ocho, tal y como afirmaba Roig y ha sido aceptado por los críticos posteriores que mencionan estas traducciones, Augier (1993: 580) y Méndez (64-65).

14 Claude Fauriel, Chants populaires de la Grèce recueillis et publiés avec une traduction française, des éclaircissements et des notes par Claude Fauriel, Paris 1824, vol. I, p. XXV. 
según explica en el prefacio que abre su obra, el cual constituye un ferviente alegato filoheleno, que esa materia prima que ofrece Fauriel puede ser adaptada en la lengua de recepción concediéndole el arte, el color y la gracia que la conviertan en una lectura agradable y duradera en el recuerdo. Asimismo, también especifica que ha seleccionado los cantos de Fauriel que mejor retratan los usos, las costumbres y a los más famosos cleftes griegos, y que los ha precedido de los cantos que relatan la ruina de los suliotas, foco primigenio de "la insurrección general de los Helenos", y que a su vez le han inspirado la tragedia los Martyrs de Souli ${ }^{15}$.

Así pues, la presencia de un ejemplar de los Chants Héroïques de Lemercier en el archivo personal de José María Heredia todavía le confiere mayor realce, si cabe, como poeta revolucionario que canta a la libertad influido directamente por los acontecimientos que estaban teniendo lugar en Grecia en aquellos mismos momentos en los que él luchaba por la independencia de Cuba.

Sin otro afán que el de insertar en mi tesis doctoral una nota a pie de página con la signatura que debería identificar ese libro entre los fondos del Museo Nacional de La Habana, entré en su página web. No obstante, al no encontrar ningún enlace hacia su biblioteca, decidí escribir a la Biblioteca Nacional José Martí, donde también se conserva un fondo herediano. Tuve la enorme suerte de que respondiera a mi correo la Licenciada Deborah Gil, del Departamento de Referencias, quien se ofreció a contactar con sus compañeros del Museo Nacional para localizar el libro. Sin embargo, para su sorpresa, y también la mía, ese libro ya no se encontraba en el Museo. A partir de ahí comenzó una operación de rastreo sobre cuyos avances la Licenciada Gil me iba informando de manera puntual por medio del correo electrónico. Debo recalcar, por tanto, que sólo gracias a su profesionalidad e implicación puedo ofrecer aquí tanto la ubicación exacta como las imágenes y los datos materiales de ese libro en el que Los Mártires de Suli viajaron hasta La Habana ${ }^{16}$.

En 1913, los nietos de José María Heredia donaron al Museo Nacional algunas pertenencias de su abuelo entre las que se encontraba el libro que nos ocupa. Allí lo consultaron González del Valle en 1938, y Roig en 1940. En 1964 fue trasladado al

${ }^{15}$ N.L. Lemercier, Chants hérö̈ques des montagnards et matelots grecs, traduits en vers français, Paris 1824, pp. 5-8. Su tragedia lleva por título Les Martyrs de Souli ou L'Épire moderne, Paris 1825. En ese mismo año, Fauriel publica el segundo volumen de su obra: Chants populaires de la Grèce moderne. Tome II: Chants historiques, romanesques, et domestiques, Paris 1825, en el que Lemercier vuelve a inspirarse para su Suite des chants héroïques et populaires des soldats et matelots grecs, Paris 1825.

${ }^{16}$ La Licenciada Gil, a su vez, desea expresar su agradecimiento a su compañero de la Biblioteca Nacional Don Tomás Rodríguez, y también a Doña Cristina Ruiz Gutiérrez, Jefa del Centro de Información "Antonio Rodríguez Morey" del Museo Nacional de Bellas Artes, quien los orientó en la búsqueda de los fondos que pasaron del Museo al Archivo Nacional, así como al resto de compañeros que los atendieron en el Archivo. 
Archivo Nacional de La Habana, donde se encuentra hoy en día: Caja o legajo $\mathrm{N}^{\circ}$ 16; $\mathrm{N}^{\mathrm{o}}$ de orden: 49. No obstante, el libro cayó en tal olvido que en 1993 el estudioso Ángel Augier todavía lo ubica en el Museo Nacional, cuando hacía casi treinta años que ya no estaba allí (Augier, 1993: 580).

Quizá la razón de este olvido radique en que Roig afirma que Heredia nunca publicó ni mencionó estas traducciones en su abundante correspondencia, y aunque tuvo noticia de que en los índices de El Iris de México, periódico donde había colaborado Heredia, aparecía el título La Muerte de Despo, carecía entonces de los medios que le permitieran comprobar si se trataba de la misma pieza (Roig: 188). Así pues, para encontrar el origen de los Cantos de Suli en español sólo hacía falta seguir la pista que Roig ya había proporcionado en 1940, pero todavía en 2003 Roberto Méndez, que no obstante es uno de los mejores críticos de Heredia, afirma que "la debilidad de los textos, que son poesía de propaganda a favor de la causa helénica, fue quizá la razón por la que el joven poeta jamás los publicara" (Méndez: 64-65). Sigamos, entonces, la pista de Roig.

\section{José María Heredia y el filohelenismo carbonario (El Iris, México 1826).}

A finales de 1825 José María Heredia conoció en México a Claudio Linati y Fiorenzo Galli, dos carbonarios italianos que ya llevaban dos exilios a sus espaldas. Ambos huyeron de Italia cuando las tropas austriacas aplastaron la revolución en el Piamonte en 1821 para refugiarse en España, donde la suerte tampoco les sonrió. En 1823 se alistaron en el regimiento del General Mina para repeler en Cataluña la invasión de las tropas francesas del Duque de Angulema, quien restituyó a Fernando VII como rey absoluto cumpliendo órdenes de la Santa Alianza. Después de la derrota, Galli pudo huir, pero Linati fue capturado y llevado a un campo de prisioneros en el sur de Francia.

Cuando a principios de 1824 fue liberado, Linati escribió a Lord Byron y al Comité Filoheleno de Londres solicitando ayuda económica para ir a luchar a Grecia, pero no debió de recibir respuesta ${ }^{17}$. Después de vagabundear por Francia como persona non grata, llegó hasta Bruselas, donde la embajada de México le invitó en su calidad de artista — durante su estancia en París llegó a ser alumno de Jacques-Louis David - para introducir allí el arte de la litografía. Linati aceptó sin dudar, llegando a Veracruz a finales de $1825^{18}$, y allí se reencontró por fortuna con

17 Claudio Linati, pp. 97-98; esto cuenta Linati en una carta que dirigía a su amigo Panizzi en Londres, fechada en Montpellier el 20 de abril de 1824. Lord Byron moría en Missolonghi (Grecia) el 19 de abril, esto es, un día antes de que Linati redactara esta carta a su amigo.

${ }^{18}$ Claudio Linati, pp. 104-110; cartas a Panizzi en Londres, fechadas en México, 22 de septiembre de 1825 , y 5 de enero de 1826. 
su amigo Fiorenzo Galli, que había hallado protección trabajando en el negocio minero.

Galli ya había ejercido en España como periodista ${ }^{19}$, y entre los dos fundaron $E l$ Iris, iniciativa a la que se sumó José María Heredia. La primera revista literaria ilustrada de México vio la luz en febrero de 1826 con el afán de divulgar contenidos de interés general - ciencia, literatura, teatro, etc.-, y "ofrecer en particular al bello secso una distracción agradable" ${ }^{20}$. No obstante, también fue utilizada como tribuna política, ya que sus redactores pensaban que la mejor manera de servir a su patria de adopción era aportarle los conocimientos y la experiencia adquiridos en su lucha por la libertad.

Las litografías que Linati incluyó en El Iris demuestran esta variedad de intereses, pues presentan tanto figurines de modas, como los retratos de los caudillos de la revolución que terminarían cimentando la iconografía patriótica de México. En realidad, el objetivo de los tres redactores era ilustrar al pueblo no sólo en cultura general, sino también en política, con el fin de implicarlo en la conservación de la libertad que tanto esfuerzo había costado conquistar. Los italianos, por experiencia propia, sentían como un peligro real e inminente las peticiones de ayuda que Fernando VII lanzaba a la Santa Alianza con el fin de reconquistar México, algo a lo que los políticos mexicanos, enzarzados en sus luchas internas por el poder, no daban la suficiente importancia ${ }^{21}$. El cubano, por su parte, defendía que Cuba debía ser liberada del dominio español por una expedición conjunta de fuerzas venezolanas y mexicanas, pues la isla sería empleada como cabeza de puente por las tropas enviadas para emprender esa reconquista, lo que haría peligrar la libertad de toda América ${ }^{22}$.

Éstas son las ideas que se van desgranando a lo largo de varios números de $E l$ Iris, pero, consciente del impacto que una imagen puede llegar a causar, Linati plasma en una litografía alegórica su visión personal de la Tiranía, a la que representa como un monstruo con patas de cabra aconsejado por un fraile y por un diablo, que sostiene un cetro de hierro y pisa con su pezuña derecha un libro cuyo

${ }^{19}$ Fiorenzo Galli participó en El Europeo (Barcelona, octubre de 1823-abril de 1824), junto con los catalanes Carlos Aribau y Ramón López Soler, el austriaco Karl Ernest Kock, y el también piamontés exiliado Luigi Monteggia. Vd. El Europeo.

${ }^{20} \mathrm{H}$ [eredia], "Introducción”, El Iris, I, no 1, 4 de febrero de 1826, p. 1. Reproduzco los textos respetando la ortografía original.

21 El napolitano Orazio d'Atellis, también exiliado en México, colaboró con los redactores de El Iris en este intento de alertar a los poderes mexicanos de la amenaza que sobre ellos se cernía desde Europa. La intromisión en los asuntos internos mexicanos les valdría a los tres italianos la expulsión del país. $V d$. Solà.

${ }^{22} \mathrm{H}$ [eredia], "Política. Mensage del Presidente Adams a la cámara de representantes de los Estados Unidos del Norte sobre el Congreso de Panamá", El Iris, I, nº 13, 29 de abril de 1826, pp. 129-132. Cf. Claps (24-25). 
título reza los Derechos del Hombre. Su trono se alza sobre calaveras, y está rodeado por el coro estremecedor de todas sus víctimas: los líderes liberales aparecen ahorcados, y, al fondo, entre el humo de las explosiones, se vislumbra Grecia $^{23}$.

En la ideología de los revolucionarios italianos — carbonarios y comuneros— ${ }^{24}$, forjada sobre la base del iluminismo romántico y que constituiría el germen del futuro Risorgimento, el filohelenismo disfrutaba de un papel protagonista. El alzamiento de Grecia, su establecimiento como nación libre e independiente, y su regeneración dentro de los moldes de la cultura europea fundada sobre las bases de la Antigüedad Clásica, reflejaban el ideal que deseaban alcanzar: una Italia libre y unida que remedara la antigua Roma republicana como parte fundamental también de esa cultura europea fundacional. Ese ideal italiano de libertad venía a su vez marcado por el universalismo, ya que todos los pueblos tenían derecho a ser libres, y para ello era necesario que la libertad fuera arraigando nación por nación creando un espíritu común que derrotara de una vez por todas al despotismo, de ámbito también transnacional. Desde su perspectiva internacionalista y sin fronteras, consideraban que, dado que todos los tiranos se aliaban para oprimir a sus pueblos, los pueblos, a su vez, debían unirse para derrocar a los tiranos, y, en consecuencia, cualquier tierra era buena para luchar por el afianzamiento de la libertad. Después del entusiasmo generalizado que provocaron las revoluciones liberales de 1820, la invasión austriaca de Nápoles y el Piamonte destruyó las esperanzas puestas en la propia patria italiana, y la ilusión revolucionaria se centró en la Península Ibérica, pues tanto España como Portugal conseguían mantener aún un Estado constitucional. Y cuando estas revoluciones también fracasaron, los únicos horizontes que quedaban abiertos a la libertad eran Grecia y América.

\section{Sentido y función del Apóstrofe a la Grecia y La muerte de Despo.}

El pensamiento de Fiorenzo Galli y de Claudio Linati es paradigmático de esta concepción revolucionaria, y no debemos olvidar que Linati se encontraba en México porque en su momento no dispuso de medios para acudir a Grecia. Por otra parte, ya hemos visto también lo que Grecia significaba para Heredia. Para los tres redactores, en definitiva, la lucha griega encarnaba la batalla suprema entre libertad y esclavitud, y las continuas referencias a ella trufan todos los números de El Iris.

Por eso, cuando a finales de abril de 1826 llegan a México noticias de que Inglaterra se declara neutral ante el conflicto griego, y de que la revolución atraviesa un momento crítico debido a la invasión del egipcio Ibrahim y al apoyo

${ }^{23}$ El Iris, I, no 11,15 de abril de 1826.

${ }^{24}$ La carbonería y la comunería fueron las dos sociedades secretas que instigaron las revoluciones en Nápoles y en el Piamonte en julio de 1820 y marzo de 1821, respectivamente. 
europeo que éste recibe, los redactores ven materializada la amenaza de la que querían alertar a sus lectores mexicanos. Galli abre el $\mathrm{n}^{0}$ del 20 de mayo con el artículo "Europa" en el que defiende que el poder de la Santa Alianza reside en su unidad $^{25}$, y continúa Linati con un texto que titula "Apóstrofe a la Grecia”, en el que expresa su hondo dolor por ella, pues después de haberse alzado contra sus tiranos al cabo de trescientos años de esclavitud y de haberse regenerado, sufre el ataque de otros tiranos hermanados con el que acababa de caer. Y con Grecia se pierde de nuevo la esperanza de la humanidad ${ }^{26}$.

Dando un sorprendente giro final a su artículo, de contenido estrictamente político, Linati cierra su Apóstrofe exhortando al "secso encantador" a que llore por Grecia, y ofrece a las "ninfas del Anáhuac" un himno de los griegos modernos, $L a$ muerte de Despo. En él, se exalta el heroísmo de una mujer que, luchando en el campo de batalla, prefiere morir antes que someterse a sus opresores con el fin de dar a sus hijas un ejemplo sublime de dignidad para que la sigan en la muerte salvando su honor.

Las fuerzas combinadas de Galli y de Linati están lanzando así una seria advertencia a la libre América: si un pueblo consigue liberarse, los tiranos se unirán para volverlo a someter. América, cuya lucha por la independencia ha sido siempre equiparada a la de Grecia, puede llegar a encontrarse sometida de nuevo al despotismo después de haber paladeado el sabor de la libertad. La elección de $L a$ muerte de Despo entre todos los poemas de los Chants Hérö̈ques de Lemercier no es gratuita. Cumpliendo con uno de los objetivos de la revista, Linati incluye material dirigido a mujeres, pero esta vez va mucho más allá de sugerirles cómo deben acicalarse o qué deben leer: les está enseñando una actitud a imitar, un modelo a seguir. Resulta muy significativo además que en la publicación en El Iris la "magnánima Despo" del original francés haya perdido su epíteto y devenido tan sólo en "Despo", lo que quizá encubra la intención de mostrarla no como una heroína que inspira admiración, pero con la que es difícil identificarse, sino como una simple mujer y madre capaz de actos heroicos a la que cualquier otra puede emular.

Con toda seguridad, en la mente de Linati ya se había llegado a concretar la idea de que es la mujer la que educa en valores a las siguientes generaciones ${ }^{27}$, pero su afán de involucrarla en la lucha contra el opresor responde también a su convicción

${ }^{25}$ G[alli], "Europa”, El Iris, II, no 19, sábado 20 de mayo de 1826, p. 42.

${ }^{26}$ L[inati], El Iris, II, no 19, 20 de mayo de 1826, pp. 42-44.

${ }^{27}$ Esta idea se encuentra plenamente desarrollada en el artículo, sin firma, "Sobre la educación de las niñas" de El Europeo, III, n ${ }^{\circ}$ 16, 24 de abril de 1824, pp. 121-125, el periódico barcelonés en el que había participado Fiorenzo Galli: "Si consideramos al bello sexo destinado a las importantes funciones de madre, hallaremos aún nuevos motivos para exigir de él conocimientos de un orden superior. Las madres son las maestras naturales de los hijos. Ellas cuidan de su niñez, ellas les infunden las primeras ideas". 
de que todos, hombres, mujeres y niños, debían estar dispuestos a sacrificarse por el honor y la libertad en el campo de batalla, puesto que la supervivencia de la nación dependía ahora ya de la sociedad en su conjunto ${ }^{28}$.

Podemos afirmar, en conclusión, que la guerra griega y el sentimiento filoheleno son un referente continuo para los movimientos independentistas americanos, que recurren a ellos como paradigma de prestigio según las necesidades del momento. Heredia cantó a la Grecia insurrecta para instigar la insurrección en Cuba y conquistar la libertad, mientras que Linati transplanta el modelo griego a México con el fin de inspirar el espíritu de resistencia y honor necesario para custodiar la independencia ya conquistada. De esta manera, los desahuciados de la revolución consiguen expresar a través del martirio de la suliota Despo que la América libre y Grecia eran ya los únicos espacios, reales o míticos, por los que merecía la pena morir.

\section{Cuatro preguntas sin respuesta.}

Para finalizar, plantearé cuatro preguntas sin respuesta todavía sobre este ejemplar habanero de los Chants Héroïques de Lemercier y las traducciones que contiene. No obstante, es muy posible que estas respuestas carezcan de importancia aún en el caso de que en un futuro llegáramos a tener los suficientes elementos de juicio que nos permitieran contestarlas; lo verdaderamente importante de ese libro es que, en un momento dado, fue la expresión material de la afinidad de intereses y opiniones entre personas de orígenes muy distintos que compartieron un breve trayecto del camino en su búsqueda de la libertad.

1) ¿Quién fue el traductor del ciclo suliota de los Chants Hérö̈ques?

En El Iris, La muerte de Despo aparece firmada por Linati, pero la caligrafía de las traducciones que figuran en el ejemplar habanero de Lemercier se corresponde con la de Heredia. Linati podía traducir al español y al italiano, pero, aunque Heredia sí tradujo del italiano, no creo que lo dominara lo suficiente como para que lo empleara como lengua meta en una traducción. Podríamos incluso pensar que Heredia tradujo los siete poemas al español y Linati los dos al italiano, pero por una observación de la Licenciada Deborah Gil sabemos que la caligrafía de las traducciones españolas es idéntica a la de las italianas, aunque con una curiosa diferencia: las españolas están escritas con tinta, y las italianas a lápiz. ¿Las tradujo

${ }^{28}$ Galli proponía para preservar la libertad de México una educación basada en el modelo espartano en el que los niños serían instruidos tanto en valores morales como en disciplina física, educación científica y civil, incluyendo a las clases pobres, a las que se les enseñaría el manejo de las armas para que pudieran asumir la defensa nacional. Claps (1720) ofrece una síntesis de todas las ideas pedagógicas que se van exponiendo a lo largo de todos los números de El Iris. 
Linati y Heredia copió los textos en el ejemplar? El hecho de que el texto final de La muerte de Despo que se publicó en El Iris presente mejoras métricas con respecto a la traducción manuscrita del libro podría apoyar esta hipótesis, pues Heredia bien pudo corregir la versión que finalmente se imprimiría si detectó algunos fallos de versificación en la primera traducción de Linati mientras la copiaba en el libro.

De la misma manera que los estudiosos de Heredia no han dado gran importancia a las traducciones del ciclo de Suli, los estudiosos de Linati, que desde luego desconocen por completo la existencia del ejemplar de Lemercier en el archivo herediano, tampoco se han preocupado demasiado del poema La muerte de Despo. Considerándola una "pedestre narración del sacrificio de una heroica mujer", Arnaldo Barilli llega a afirmar que se trata de una composición original del propio Claudio Linati, quien la hace pasar por una traducción del griego moderno para dotarla de un encanto mayor ${ }^{29}$.

2) ¿Cuándo llegaron a México los Chants Héroïques de Lemercier?

Los Chants Héroïques comenzaron a circular a finales de 1824. Heredia pudo haberlo adquirido en Estados Unidos durante los primeros meses de 1825, pues las novedades literarias europeas circulaban de forma inmediata en Boston y en Nueva York. Linati, por su parte, pasó toda la primera mitad de 1825 entre Francia y Bruselas, desde donde pudo llevarlo consigo en su viaje a México.

3) ¿Cómo acabó el libro en tal estado de deterioro y en poder de Heredia?

Dado que resulta imposible determinar quién de los dos fue su primer dueño, sólo puedo aventurar una solución, un tanto salomónica, que pueda justificar su estado. Aunque Heredia abandonó El Iris por diferencias personales con los italianos, parece que la ruptura fue amistosa. Si Heredia y Linati estaban interesados en el libro, cabe la posibilidad de que se lo repartieran entre los dos. Linati, con sus preocupaciones políticas, se quedó con la introducción, donde Lemercier diserta sobre la relación intrínseca entre filohelenismo y libertad, mientras que Heredia, siempre más poeta, decidió conservar los poemas. De esta manera, la desencuadernación del libro para su reparto explicaría su deterioro, pues en el bloque de los poemas, el conservado por Heredia, faltan precisamente cinco hojas al principio (pp. 15-24) y otras cuatro hojas al final (pp. 177-184) ${ }^{30}$. Resulta lógico

${ }^{29}$ A. Barilli, "Claudio Linati giornalista nel Messico", en Claudio Linati, pp. 185-242. La cita en p. 214.

${ }^{30}$ Gracias al dato que Roig (192), cf. supra nota 12, añade a la descripción del libro que ya había hecho González del Valle, sabemos que a ese ejemplar le faltan 8 páginas al final, pues la edición original de los Chants Hérö̈ques de Lemercier llega hasta la página 180 y sí que incluye, además, un índice de tres páginas. 
pensar que estas páginas iniciales y finales, desprotegidas de su cubierta, llegaran a desaparecer a lo largo de los diversos traslados de Heredia por el interior de México, quedando el libro en el estado en el que lo conocemos hoy. De hecho, gracias a la fotografía de la primera página de ese ejemplar que me envió la Licenciada Deborah Gil, he podido comprobar que desde 1940 hasta ahora aún se ha perdido al menos otra hoja más, pues Roig transcribió completa la traducción del poema Derrota de Ali de Tebelén, mientras que en la primera hoja conservada sólo pueden leerse ahora los versos finales.

Por otra parte, la Licenciada Gil me informó también de que este libro no parece estar registrado en el catálogo que José María Heredia realizó de su propia biblioteca en 1833, que se conserva en el fondo de Manuscritos de la Biblioteca Nacional José Martí de La Habana, y que es tan meticuloso que refleja incluso el precio que el poeta pagó por cada libro. No aparece nada relacionado con Lemercier, con el título de la obra, ni bajo un epígrafe genérico de "poemas en francés", a pesar de que Heredia debió de saber en su momento de qué libro se trataba. ¿Lo omitió por error en la catalogación o no lo tenía en su poder en ese momento? ¿Cómo apareció después entre los papeles que su viuda llevó de vuelta a Cuba?

4) ¿Por qué Heredia nunca publicó estas traducciones?

A lo largo de su vida, Heredia redactó al menos cinco revistas para las que necesitaba todo el material posible que cayera en sus manos, y escribió y tradujo cantidades ingentes de textos para cumplir los plazos de publicación. Así pues, resulta extraño que nunca llegara a echar mano de estas traducciones que ya tenía en archivo, y más sorprendente aún cuando en un par de artículos divulgó en México la obra de Népomucène Lemercier ${ }^{31}$. Si las traducciones las hizo en realidad Linati, es posible que Heredia nunca las publicara por respetar su autoría; si las traducciones las hizo Heredia, hay que buscar otras razones.

Es probable que estos poemas cayeran en el olvido cuando la situación política en el Caribe se calmó en 1829. Fernando VII renunció definitivamente a reconquistar América después de un estrepitoso fracaso, México dejó de sentir la urgencia de defenderse $\mathrm{y}$, por su parte, la acomodada clase criolla cubana se tranquilizó. El penoso exilio del propio Heredia funcionaba muy bien, además, como escarmiento ejemplarizante, y quizá el poeta pensó que Los Mártires de Suli, trágicos protagonistas de una gloriosa derrota, pero derrota al fin y al cabo, no serían el estímulo más idóneo para reavivar de nuevo las veleidades independentistas.

31 "Poetas franceses modernos", Miscelánea (Tlalpam), $1^{\mathrm{a}}$ época, II, $\mathrm{n}^{\mathrm{o}} 8$ (abril 1830), pp. 99-100; y “Literatura francesa contemporánea”, Miscelánea (Toluca), 2 época, I, no 3 (agosto 1831), p. 86. 
La era de las revoluciones en la que Grecia fue referente transcontinental durante la primera mitad del siglo XIX ya había pasado. Otras estaban por venir en la segunda mitad del siglo, y entre ellas la cubana, en la que el referente fue José María Heredia y su anhelo de dejar de ser español. Él siempre quiso ser, simplemente, cubano.

\section{BIBLIOGRAFÍA}

AUGIER, Ángel.

1990 "José María Heredia: novela y realidad de América Latina", Revista Iberoamericana 56, $\mathrm{n}^{\circ}$ 152-152 (julio-diciembre 1990): 733-746.

1993 (ed.) José María Heredia. Obra poética. La Habana.

CABRERA, Yoandi.

2011 "Heredia y Delacroix: la Grecia decimonónica como factor común", Blog Nombrar las cosas. Cuaderno de crítica y poesía, entrada con fecha 11/12/2011. Enlace comprobado en mayo de 2013. http://yoandynombrar.blogspot.com.es/2011/11/heredia-y-delacroix-lagrecia.html

CLAPS ARENAS, $\mathrm{M}^{\mathrm{a}}$ Eugenia.

2001 "El Iris, periódico crítico y literario", Estudios de Historia Moderna y Contemporánea de México 21:5-29.

Claudio Linati (1790-1832), Memorie Parmensi per la Storia dil Risorgimento 13 Parma, 1935.

El Iris, Periódico crítico literario, por Linati, Galli y Heredia, Ed. facsímil. María C. Ruiz Castañeda (intr.), Universidad Nacional Autónoma de México 1986.

El Europeo (Barcelona 1823-1824). Prensa, modernidad y universalismo, Ed. facsímil. P.A. Sprague (intr.). Madrid/Frankfurt: Iberoamericana/Vervuert, 2009.

GONZÁLEZ DEL VALLE, Francisco.

1938 Cronología Herediana (1803-1839). La Habana.

LATORRE BROTO, EVA.

2011 "Los filohelenos españoles: estado de la cuestión y actualización de nómina", Erytheia. Revista de Estudios Bizantinos y Neogriegos 32: 279-319.

2012 "Los amigos de la libertad: documentos sobre el filohelenismo español (1821-1823)", Erytheia. Revista de Estudios Bizantinos y

MÉNDEZ, Roberto. Neogriegos 33: 195-251.

2003 José María Heredia. La utopía restituida. Santiago de Cuba. 
MENÉNDEZ PELAYO, Marcelino.

1913 Historia de la Literatura Hispanoamericana, 2 vols. Madrid. PÉREZ ASENSIO, Magdalena.

2010 El mito en el teatro cubano contemporáneo, Tesis doctoral. Enlace comprobado en mayo de 2013.

http://interclassica.um.es/investigacion/tesis/el mito en el teatro c

PIÑEYRO, Enrique.

ubano contemporaneo/(ver)/1

1907 “José María Heredia", Bulletin Hispanique IX, (2):186-209.

ROIG DE LEUCHSENNING, Emilio (ed.).

1940 José María Heredia. Poesías completas, homenaje de la Ciudad de la Habana en el centenario de la muerte de Heredia, 1839-1939, vol. I. La Habana.

1941 José María Heredia. Poesías completas, homenaje de la Ciudad de la Habana en el centenario de la muerte de Heredia, 1839-1939, vol. II. La Habana.

SOLÁ I PARERA, Maria Àngels.

1984 "Escocés (sic), yorkinos y carbonarios (La obra de O. de Attelis, Marqués de Santangelo, Claudio Linati y Florencio Galli en México en 1826)", Boletín americanista 34:209-244.

SUÁREZ PIÑA, Virginia Bárbara y Graciela DURÁN RODRÍGUEZ.

2008 Tradición clásica grecolatina en el teatro de José María Heredia a través de sus obras originales y traducciones", en José Vicente Bañuls y Carmen Morenilla (eds.), Teatro y sociedad en la antigüedad clásica. Valencia: Universitat de Valencia, pp. 513-534.

VALDÉS, Emilio (ed.).

1939 Antología herediana. Selección de las mejores poesías líricas. La Habana. 


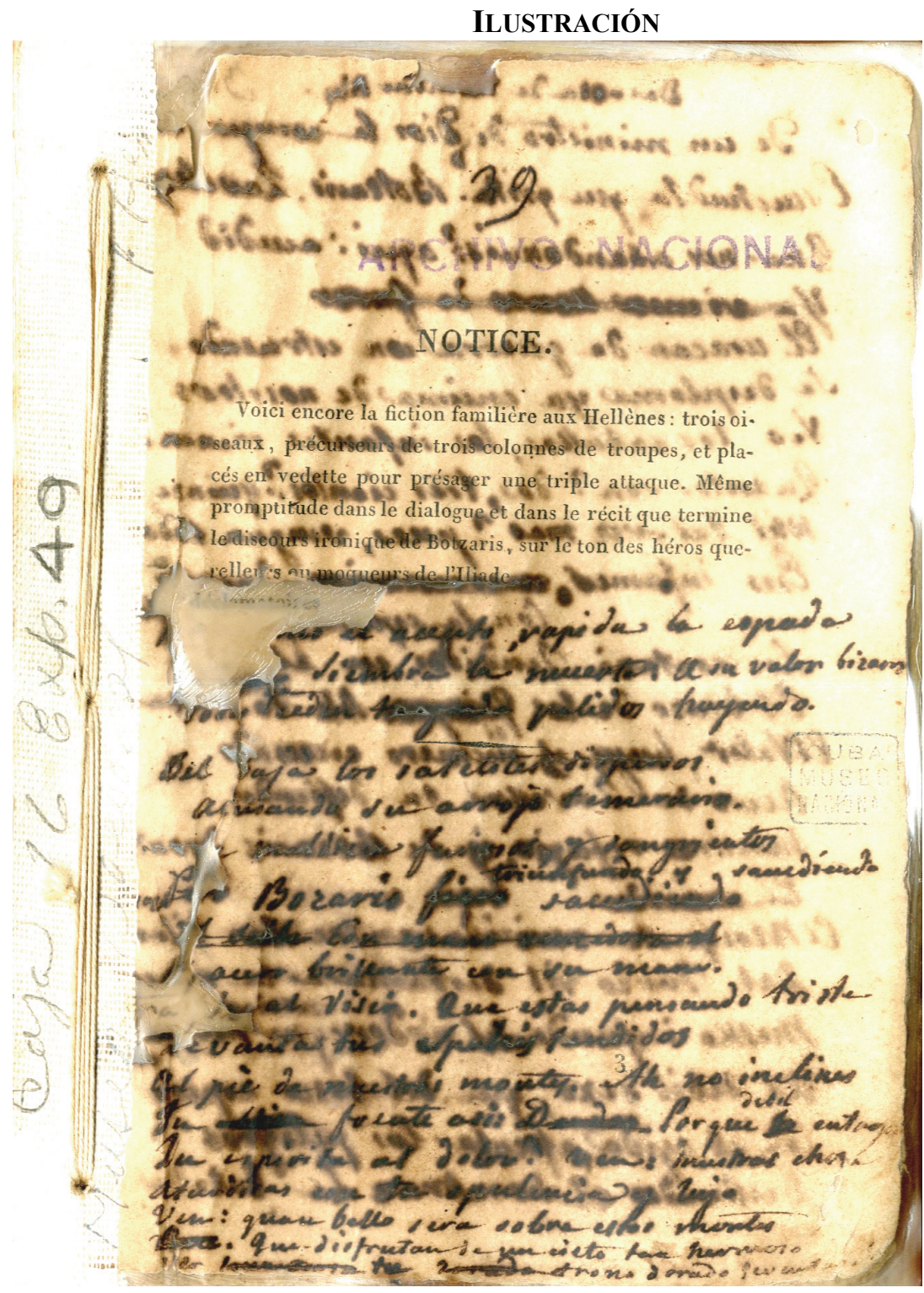

Primera página del ejemplar de Chants hérö̈ques des montagnards et matelots Grecs, de Népomucène Lemercier, que perteneció a José María Heredia. Conservado actualmente en el Archivo Nacional de Cuba (La Habana), Caja o legajo $\mathrm{N}^{\circ} 16 ; \mathrm{N}^{\circ}$ de orden 49. Foto cortesía del Archivo Nacional de Cuba y de la Licenciada Deborah Gil, de la Biblioteca Nacional José Martí de La Habana. 